\title{
JUURNAL.RU
}

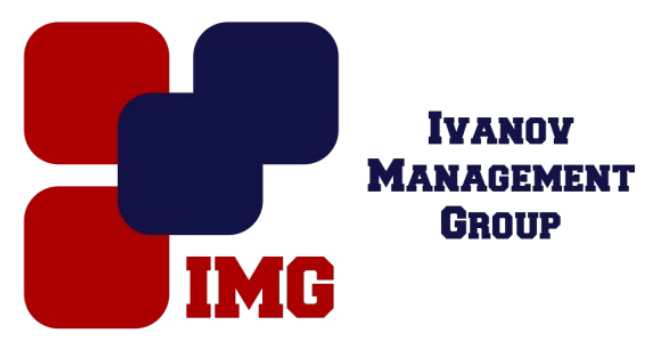

Веретенников А.И. Белгородский государственный научно-исследовательский университет Белгород, Россия

doi: 10.18411/lj-30-04-2017-1-06

idsp 000001:lj-30-04-2017-1-06

\section{Региональные особенности инвестиционной деятельности предприятий малого и среднего бизнеса}

\section{Аннотация}

В статье отмечается необходимость повышения эффективности функционирования малого и среднего бизнеса в Российской Федерации. На примере субъектов Центрально-Черноземного региона рассмотрены показатели эффективности МСБ, раскрыты их особенности для различных территорий и выявлены резервы роста и развития.

Ключевые слова: малый и средний бизнес, инвестиции, региональные особенности, эффективность функционирования

Развитие экономики в сегодняшних инновационных условиях диктует необходимость постоянного обновления производства, внедрения новых современных технологий, обеспечивающих выпуск конкурентоспособной продукции. Решить эти вопросы невозможно без активизации инвестиционной деятельности, для финансирования которой необходимы серьезные источники, получаемые на долгосрочной основе. Стоимость источников финансирования инвестиций в основной капитал в последние годы остается достаточно высокой, что затрудняет возможности предпринимателей в расширении границ своей деятельности. Вместе с тем, как на федеральном, так и региональном уровнях предпринимаются значительные попытки к расширению источников финансирования и их доступности с целью обеспечения, прежде всего, импортозамещения. 
Особенно чувствителен рассматриваемый вопрос для предприятий субъектов малого и среднего предпринимательства, ресурсы которых по сравнению с крупным бизнесом по известным причинам значительно ограничены [1].В табл. 1 представлены основные показатели деятельности указанных предприятий в 2015 г., полученные в ходе сплошного федерального статистического наблюдения субъектов малого и среднего предпринимательства в соответствии с законом «Оразвитии малого и среднего предпринимательства в Российской Федерации» от 24.07.2007 № 209-Ф3[2].

На основе статистических данных в табл. 1 рассчитаны такие показатели, как фондоотдача и инвестиции в основной капитал на 1 рубль стоимости основных фондов [3].

Таблица 1.

Основные показатели деятельности предприятий малого и среднего бизнеса в 20152.

\begin{tabular}{|c|c|c|c|c|c|}
\hline \multirow[b]{3}{*}{$\begin{array}{c}\text { № } \\
\Pi / \Pi\end{array}$} & \multirow[b]{3}{*}{ Наименование показателя } & \multirow[b]{3}{*}{$\begin{array}{l}\text { Всего по } \\
\text { эконо-мике }\end{array}$} & \multicolumn{3}{|c|}{ в том числе по категориям } \\
\hline & & & \multirow[b]{2}{*}{$\begin{array}{c}\text { средние } \\
\text { пред- } \\
\text { приятия }\end{array}$} & \multicolumn{2}{|c|}{ малые предприятия } \\
\hline & & & & всего & $\begin{array}{c}\text { из них } \\
\text { микро- } \\
\text { пред- } \\
\text { приятия }\end{array}$ \\
\hline 1 & 2 & 3 & 4 & 5 & 6 \\
\hline 1 & Выручка от реализации, млрд. руб. & 54647,8 & 10370,6 & 44277,2 & 18656,5 \\
\hline 2 & Инвестиции в основной капитал, млрд. руб. & 1348,3 & 411,2 & 937,1 & 433,1 \\
\hline 3 & $\begin{array}{l}\text { Основные фонды по полной учетной стоимости } \\
\text { на конец года, млрд. руб. }\end{array}$ & 8637,2 & 2000,5 & 6636,8 & 3 165,5 \\
\hline 4 & Фондоотдача, руб./руб. & 6,33 & 5,18 & 6,67 & 5,89 \\
\hline 5 & $\begin{array}{c}\text { Инвестиции на } 1 \text { руб. стоимости основных } \\
\text { фондов, руб./руб. }\end{array}$ & 0,16 & 0,21 & 0,14 & 0,14 \\
\hline
\end{tabular}

Как показывают данные таблицы, фондоотдача на малых предприятиях выше среднероссийского уровня $(6,67$ против 6,33$)$, а вложенные инвестиции в расчете на 1 рубль стоимости основных фондов ниже среднероссийского значения $(0,14$ против 0,16$)$, что говорит о достаточно эффективном функционировании малых предприятий.

По средним предприятиям сложилась противоположная ситуация. Здесь фондоотдача ниже среднероссийского уровня $(5,18$ против 6,33$)$, а инвестиции более существенны $(0,21$ против 0,16$)$.

Таким образом, можно сделать вывод о более эффективном функционировании малых предприятий по сравнению со средними в части рассматриваемых показателей.

Далее на примере субъектов Центрально-Черноземного региона рассмотрим региональные особенности функционирования малого и среднего бизнеса относительно осуществляемой ими инвестиционной деятельности (табл. 2) [3]. 
Региональные особенности инвестиционной деятельности и ее результативности в 2015 г.

\begin{tabular}{|c|c|c|c|c|c|}
\hline \multirow{3}{*}{ Регион } & \multirow{3}{*}{$\begin{array}{c}\text { Наименование } \\
\text { показателя, } \\
\text { (руб./руб.) }\end{array}$} & \multirow{3}{*}{$\begin{array}{l}\text { Всего по } \\
\text { экономике }\end{array}$} & \multicolumn{3}{|c|}{ в том числе по категориям } \\
\hline & & & \multirow{2}{*}{$\begin{array}{c}\text { средние пред- } \\
\text { приятия }\end{array}$} & \multicolumn{2}{|c|}{ малые предприятия } \\
\hline & & & & всего & $\begin{array}{c}\text { из них } \\
\text { микропредприятия }\end{array}$ \\
\hline \multirow{2}{*}{$\begin{array}{c}\text { Белгородская } \\
\text { область }\end{array}$} & фондоотдача & 5,87 & 3,24 & 7,30 & 7,11 \\
\hline & нвестиции* & 0,23 & 0,24 & 0,23 & 0,20 \\
\hline \multirow{2}{*}{$\begin{array}{c}\text { Воронежская } \\
\text { область }\end{array}$} & фондоотдача & 6,98 & 4,07 & 8,56 & 6,81 \\
\hline & нвестиции* & 0,32 & 0,30 & 0,34 & 0,37 \\
\hline \multirow{2}{*}{$\begin{array}{l}\text { Курская } \\
\text { область }\end{array}$} & фондоотдача & 4,05 & 2,89 & 4,70 & 5,11 \\
\hline & нвестиции* & 0,15 & 0,11 & 0,17 & 0,20 \\
\hline \multirow{2}{*}{$\begin{array}{l}\text { Липецкая } \\
\text { область }\end{array}$} & фондоотдача & 4,81 & 2,92 & 5,49 & 5,85 \\
\hline & нвестиции* & 0,40 & 0,20 & 0,47 & 0,53 \\
\hline \multirow{2}{*}{$\begin{array}{c}\text { Тамбовская } \\
\text { область }\end{array}$} & фондоотдача & 5,00 & 4,41 & 5,27 & 6,25 \\
\hline & нвестиции* & 0,45 & 0,35 & 0,50 & 0,71 \\
\hline
\end{tabular}

*инвестиции на 1 рубль стоимости основньхх фондов

Данные табл. 2 свидетельствуют о том, что ситуация по областям Центрально-Черноземного региона складывается неоднозначная. Наиболее низкий уровень инвестиций в основной капитал в расчете на 1 рубль стоимости основных фондов характерен для Курской области, но при этом и фондоотдача в данной области также самая низкая. То есть, Курская область из рассматриваемых территорий находится на последнем, пятом месте. Это прослеживается на предприятиях различных размеров.

Наиболее благоприятная ситуация характерна для Воронежской и Белгородской областей. При этом Воронежская область является лидирующей преимущественно по всем показателям фондоотдачи для предприятий разных размеров.

Несколько более скромные показатели отмечаются в Белгородской области, и она стабильно находится на втором месте по уровню фондоотдачи среди рассматриваемых областей.

При этом необходимо отметить ту особенность, что и в Воронежской, и в Белгородской областях уровень инвестиций в основной капитал на 1 рубль стоимости основных фондов значительно ниже по сравнению с другими областями (кроме Курской области). По этому показателю для Воронежской области характерно третье, а для Белгородской области - четвертое места. Это обстоятельство говорит о более высокой эффективности инвестиций в основной капитал в названных областях.

Более низкая эффективность инвестиций в основной капитал сложилась в Липецкой и Тамбовской областях. По уровню фондоотдачи на третьем месте среди субъектов Центрально-Черноземного региона находится Тамбовская 
область, а на четвертом - Липецкая область. Для этих субъектов характерен и более высокий уровень инвестиционных затрат. В Тамбовской области он самый высокий среди рассматриваемых пяти субъектов, то есть, находясь на третьем месте по уровню фондоотдачи, эта область затрачивает для достижения данного показателя максимальные инвестиции, что не является эффективным.

В Липецкой области ситуация по соотношению «затраты-эффективность» примерно аналогичная, так как, находясь на четвертом месте по уровню фондоотдачи, для нее характерно второе место по затратам.

На основе изложенного выше можно сделать следующие выводы:

- уровень фондоотдачи на малых предприятиях значительно выше по сравнению со средними показателями по всем областям и показателями их средних предприятий;

- уровень инвестиций в основной капитал на 1 рубль стоимости основных средств, наоборот, на малых предприятиях выше по сравнению со среднеобластными показателями и показателями средних предприятий;

- фондоотдача, как показатель эффективности функционирования малого бизнеса, зависит не только от вложения инвестиций, но и от эффективности их использования;

- наиболее эффективным является функционирование малого и среднего бизнеса в Воронежской и Белгородской областях среди субъектов Центрально-Черноземного региона.

Проведенный анализ свидетельствует о различном уровне эффективности функционирования малого и среднего бизнеса в регионах. Для повышения общей результативности работы этого важного сектора экономики необходимо изучение опыта управления малым и средним бизнесом, имеющегося в соседних территориях, и его реализация в практической деятельности. 
1. Логачев К. И., Веретенников А. И. Совершенствование отраслевой и территориальной структуры малого бизнеса в российской экономике // Научный результат. Экономические исследования. - T.2, №4, 2016.URL: http://researchresult.ru/journal/economic/annotation/953/ - 0,59.

2. О развитии малого и среднего предпринимательства в Российской Федерации. Федеральный закон РФ от 24.07.2007 № 209-Ф3 [Электронный ресурс]. Режим доступа: http://base.consultant.ru

/cons/cgi/online.cgi?req=doc;base=LAW;n=157188;dst=0;ts=F93EC7FCC494C91289B32E3 DCF581690;rnd =0.09433171525597572.

3. Предварительные итоги сплошного наблюдения за деятельностью малого и среднего бизнеса за 2015 год [Электронный ресурс]. Режим доступа:http://www.gks.ru/free_doc/new_site/business/prom/small_business/itog2015/itogspn2015.html. 